\title{
Temperature-programmed surface reactions of methanol and dimethyl ether on bifunctional catalysts for the direct synthesis of dimethyl ether from syngas
}

\author{
Olga Vodorezova $^{1}$, Pavel Musich $^{1}$, Natalia Karakchieva ${ }^{1,2}$, Lothar Heinrich $^{3}$ and Irina Kurzina ${ }^{1, *}$ \\ ${ }^{1}$ National Research Tomsk State University, 634050, Tomsk, Russia \\ ${ }^{2}$ Siberian Research Institute of Agriculture and Peat - branch of the Siberian Federal Scientific Center of Agro-Bio Technologies \\ of the Russian Academy of Sciences, 634050, Tomsk, Russia \\ ${ }^{3}$ Westfalische Wilhelms-Universitat Munster, Institute of Biochemistry, Munster, Germany
}

\begin{abstract}
Dimethyl ether (DME) can be used as a replacement for diesel fuel in transportation. The catalytic effectiveness of bifunctional catalysts for DME one-stage synthesis from carbon monoxide and hydrogen was estimated in the paper. Bifunctional catalysts CuZnAl/HZSM-5, $\mathrm{CuZnAlCr} / \mathrm{HZSM}-5$, and CuZnAlZr/HZSM-5 were obtained by physical mixing of $\mathrm{CuZnAl}(\mathrm{Cr} / \mathrm{Zr})-$ Ox and HZSM-5 components and were characterized by BET, X-ray diffraction, and temperatureprogrammed surface reaction methods. Based on the TPSR results, the mechanism of the interaction of methanol and DME with the surface of the bifunctional catalyst was studied. It was found that the temperature range of the greatest catalytic activity was $240-260{ }^{\circ} \mathrm{C}$.
\end{abstract}

\section{Introduction}

Research on alternative fuels has mainly started due to ecological and economic considerations. The synthesis and application of synthesized dimethyl ether (DME) are relevant to developing alternative energy [1]. DME is widely used, environmentally friendly, and ultrapure product substituting for automotive and household fuel. There are two methods of producing DME as a two-step one consisting of methanol synthesis from syngas followed by dehydration, and one-step method involving synthesizing DME directly from syngas attracting the attention of researchers and manufactures in many countries [2]. The development of bifunctional catalysts (BC) for the direct synthesis of DME has received great attention in the literature.

The synthesis of DME involves the following reactions:

Methanol synthesis:

$\begin{array}{ll}\text { (1) } & \mathrm{CO}+2 \mathrm{H}_{2} \leftrightarrow \mathrm{CH}_{3} \mathrm{OH} \\ \text { (2) } & \mathrm{CO}_{2}+3 \mathrm{H}_{2} \leftrightarrow \mathrm{CH}_{3} \mathrm{OH}+\mathrm{H}_{2} \mathrm{O}\end{array}$

Methanol dehydration to DME:

(3) $2 \mathrm{CH}_{3} \mathrm{OH} \leftrightarrow \mathrm{CH}_{3} \mathrm{OCH}_{3}+\mathrm{H}_{2} \mathrm{O}$

Reverse water gas shift:

(4) $\mathrm{CO}_{2}+\mathrm{H}_{2} \leftrightarrow \mathrm{CO}+\mathrm{H}_{2} \mathrm{O}$.

The most widely studied catalysts for the direct synthesis of DME use $\mathrm{CuO}-\mathrm{ZnO}-\mathrm{Al}_{2} \mathrm{O}_{3}$ as function methanol formation (1 and 2 reactions). Research has been focused on increasing their stability, improving the dispersion of $\mathrm{Cu}$ and incorporating different metallic promoters (Cr, Fe, $\mathrm{Mg}, \mathrm{Mn}$ and $\mathrm{Zr}$ oxides) [3-7]. For the function methanol dehydration (3 reaction), catalysts of different porous structure are used $\left(\gamma-\mathrm{Al}_{2} \mathrm{O}_{3}\right.$, silicaalumina, HZSM-5, NaHZSM-5, mordenite, HY, ferrierite, HMCM-22, SAPOs and $\mathrm{ZrO}_{2}$ ) [8-12]. Conventionally, $\mathrm{BC}$ are used, whose particles are prepared by physical mixture of the methanol formation and dehydration catalysts, and subsequent pelletizing [13].

The reactions mechanisms wich occurring on the catalysts surface during synthesis of methanol and its dehydration are examined in the literature. However, the processes on the surface of the $\mathrm{BC}$ with parallel reactions of formation and dehydration of methanol have not been fully considered [13-17].

\section{Materials and methods}

In our work we synthesized three types of $\mathrm{BC}$ by physical mixture adding methatol synthesis catalyst (CuZnAl-Ox (CZA), CuZnAlCr-O ${ }_{x}$ (CZAC), and CuZnAlZr-O ${ }_{x}$ (CZAZ) to methanol dehydration catalyst (HZSM-5). BCInitial powders were individually grounded in an agate mortar for $15 \mathrm{~min}$ followed by pelletizing of the solid mixture. Chemicals as CZA, CZAC, and CZAZ were prepared by co-precipitation [ in aqueous solutions containing appropriate metal nitrates in constant $\mathrm{pH}$ and temperature as described in [18]. A ZSM-5 zeolite (Institute of Petroleum Chemistry of the Siberian Branch of the RAS) in its protonic form was used as methanol dehydration catalyst as described in previous studies $[11,12]$. The selection of the conditions

* Corresponding author: kurzina99@mail.ru 
for carrying out the reaction was based on theoretical calculations [19].

Porous structure (pore volume, V, and size, $\mathrm{d}$,) and specific surface area $\left(\mathrm{S}_{\mathrm{BET}}\right)$ of the catalysts were determined from the data of nitrogen adsorption isotherms observed at $-196{ }^{\circ} \mathrm{C}$, using the automatic TriStar II 3020 analyzer of Micromeritics (USA). The value of the specific surface area was determined by the Brunauer-Emmett-Teller (BET) theory method from nitrogen adsorption X-ray phase analysis was performed with a Rigaku Miniflex 600 using $\mathrm{CuK} \alpha$-radiation with a monochromator. The size of the ordered domains (r) was evaluated using the Scherer method.

The catalytic effectiveness, estimated as yield of DME, BCwas tested using a high-pressure fixed-bed reactor at pressure of $3 \mathrm{MPa}$, temperature of $260{ }^{\circ} \mathrm{C}$, weight ratio ' $\mathrm{H}_{2} / \mathrm{CO}{ }^{\prime}=' 2: 1$ ', and weight hour space velocity of $576 \mathrm{~h}^{-1}$. Gaseous hydrogen and carbon monoxide were used as components of the initial reaction mixture. A catalyst with a particle size in the range of $0.5-1.0 \mathrm{~mm}$ was used, and $5.0 \mathrm{~cm}^{3}$ of the samples were loaded into the reactor. Gas chromatographic analysis of the product was carried out on a gas chromatograph Crystal 5000.2 [20].

Temperature-programmed surface reaction (TPSR) was used to study the interaction of methanol and DME with the surface of the catalysts. TPSR was carried out using a chemisorption analyzer Chemisorb 2750 (Micromeritics, USA) combined with the quadrupole mass spectrometer UGA-300 (Stanford Research System, USA). Prior to the experiment, the sample was treated with a hydrogen-containing gas stream $\left(10 \% \mathrm{H}_{2}\right.$ in Ar) at $350{ }^{\circ} \mathrm{C}$. Adsorption of DME was carried out at $100{ }^{\circ} \mathrm{C}$ for $30 \mathrm{~min}$ in adsorbate gas stream of at the rate of $20 \mathrm{ml} / \mathrm{min}$. Methanol (99.9 purity, Acros Organics) was injected with a microsyringe through an evaporator at $100^{\circ} \mathrm{C}$ into a stream of an inert carrier gas (He). After adsorption, the sample was left in the carrier gas stream for $30 \mathrm{~min}$ to remove the residues of the adsorbate. The thermo-desorption experiment with a mass spectrometric analysis of the desorption products was carried out in a stream of He gas at the rate of $20 \mathrm{ml} / \mathrm{min}$ and a linear heating rate of $10 \%$ min from 100 to $500{ }^{\circ} \mathrm{C}$.

\section{Results and discussion}

The highest yield of DME (13\%) was demonstrated by the use of CZA/HZSM-5 catalyst. However, the sample modified by chromium having less DME yield (11\%) gave less content of by-products. For comparison, at 260 ${ }^{\circ} \mathrm{C}$, the DME yield was 13, 11, and $10 \%$ for CZA/HZSM-5, CZAC/HZSM-5, and CZAZ/HZSM-5, respectively. The main by-product of the reaction was carbon dioxide (Table 1).

The properties of the catalysts were associated with different phase composition and processes that occurred under catalysis conditions and led to structure-phase changes of the samples. According to X-ray analysis, obtained $\mathrm{BC}$ was a mixture of zeolite ZSM-5 and zinc oxide $\mathrm{ZnO}$ (wurtzite) with $\mathrm{CuO}$ (tenorite) as shown in Figure 1. The absence of diffraction lines of chromium, zirconium, and aluminium oxides could be explained by the low phase concentration and/or by the amorphous phase, although the $\mathrm{Zr}$-containing catalyst showed less intense reflexes of $\mathrm{ZnO}$ (Figure 1a). The diffraction lines of $\mathrm{CuO}$ and $\mathrm{ZnO}$ had a diffuse shape and overlap, which meant that the particles of the $\mathrm{CuO}$ and $\mathrm{ZnO}$ phases had high dispersity and were characterized by a low degree of ordering of the structure.

Table 1. Catalytic characteristics of catalysts for the DME synthesis

\begin{tabular}{|l|c|c|c|c|}
\hline Sample & $\begin{array}{c}\mathrm{CO} \\
\text { conversi } \\
\text { on, } \%\end{array}$ & $\begin{array}{c}\text { DME } \\
\text { yield, } \\
\%\end{array}$ & $\begin{array}{c}\mathrm{CO}_{2} \\
\text { yield } \\
\%\end{array}$ & $\begin{array}{c}\mathrm{CH}_{4} \\
\text { yield } \\
\%\end{array}$ \\
\hline CZA/HZSM-5 & 84 & 13 & 36 & 2 \\
\hline CZAC/HZSM-5 & 81 & 11 & 28 & 1 \\
\hline CZAZ/HZSM-5 & 85 & 10 & 28 & 2 \\
\hline
\end{tabular}

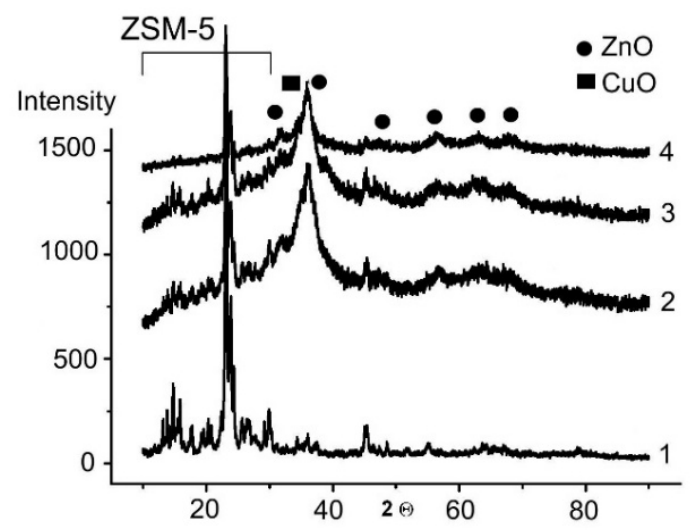

(a)

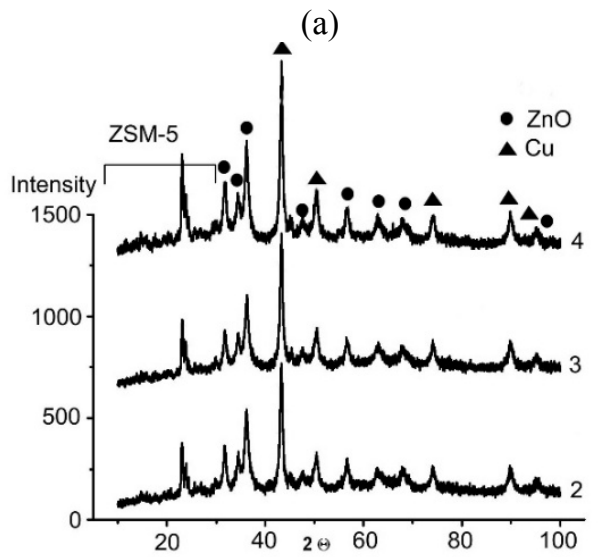

(b)

Fig. 1. XRD patterns of the BC for the DME preparation (a) before and (b) after catalysis: $1-$ HZSM-5, 2 $\mathrm{CuZnAl} / \mathrm{HZSM}-5, \quad 3-\mathrm{CuZnCrAl} / \mathrm{HZSM}-5,4-$ CuZnAlZr/HZSM-5.

After the catalytic process, the diffraction patterns of the samples showed phase reflexes in more crystallized state. The XRD showed intense peaks in the region $2 \Theta=10-30^{\circ}$ corresponding to the presence of zeolite in the catalyst. When the catalyst reacted with the reactive atmosphere, copper oxides were reduced to the metallic 
state, which was confirmed by XRD data and accompanied by a decrease in the surface area of the samples shown in Table 1. The value of the size of the ordered domains of the copper particles in the BC after catalysis was close to $\sim 13 \mathrm{~nm}$, while for the catalysts in synthesis of methanol CZA, CZAC, and CZAZ, these values were $17.2,13.6$, and $15.1 \mathrm{~nm}$, respectively.

Table 2. Structural characteristics of catalysts for the DME synthesis before and after catalysis.

\begin{tabular}{|l|c|c|c|c|}
\hline Catalyst & $\begin{array}{c}{ }^{1} \mathrm{~S}, \\
\mathrm{~m}^{2} / \mathrm{g}\end{array}$ & $\begin{array}{c}{ }^{1} \mathrm{~V}, \\
\mathrm{~cm}^{3} / \mathrm{g}\end{array}$ & $\begin{array}{c}{ }^{1} \mathrm{~d}, \\
\mathrm{~nm}\end{array}$ & $\begin{array}{c}{ }^{2} \mathrm{r}_{\mathrm{Cu}}, \\
\mathrm{nm}\end{array}$ \\
\hline CZA/HZSM-5 & \multicolumn{5}{|l|}{} \\
\hline $\begin{array}{l}\text { before } \\
\text { catalysis }\end{array}$ & 121 & 0.2 & 9 & - \\
\hline $\begin{array}{l}\text { after } \\
\text { catalysis }\end{array}$ & 90 & 0.2 & 13 & 12.5 \\
\hline CZAC/HZSM-5 & 135 & 0.2 & 7 & - \\
\hline $\begin{array}{l}\text { before } \\
\text { catalysis }\end{array}$ & 80 & 0.1 & 9 & 12.5 \\
\hline $\begin{array}{l}\text { after } \\
\text { catalysis }\end{array}$ & 135 & 0.2 & 7 & - \\
\hline $\begin{array}{l}\text { CZAZ/HZSM-5 } \\
\text { before } \\
\text { catalysis }\end{array}$ & 82 & 0.1 & 16 & 13.2 \\
\hline $\begin{array}{l}\text { after } \\
\text { catalysis }\end{array}$ & \multicolumn{5}{|l}{} \\
\hline
\end{tabular}

Further, catalysts had a high surface area with a predominance of mesopores (Table 2). The CZA/HZSM5 catalyst had a lower specific surface area compared to catalysts containing chromium and zirconium. The CZAC/HZSM-5 and CZAZ/HZSM-5 catalysts had the specific surface area of $135 \mathrm{~m}^{2} / \mathrm{g}$ and an average pore volume of $0.2 \mathrm{~cm}^{3} / \mathrm{g}$. From the presented data it can be presence of chromium and zirconium, in the coppercontaining catalyst for methanol synthesis, have led to a decrease in the size of the coherent-scattering region of the metallic copper phase [21].

Figures 2 and 3 show the desorption spectra of methanol and DME from the surface of CZAC, HZSM-5, and CZAC/HZSM-5 catalysts, accompanied by the mass spectrometric analysis of the desorption products (in the figures, the most important $\mathrm{m} / \mathrm{z}$ are shown).

The maxima of the desorption of physically adsorbed methanol $(\mathrm{m} / \mathrm{z}=31,32)$ for all three catalysts were observed on the TPSR spectrum after methanol adsorption (Figure $2 \mathrm{a}$ ) at $165 \ldots 175^{\circ} \mathrm{C}$. The spectrum of methanol desorption from the surface of CZAC had a broad peak with a maximum temperature of $197{ }^{\circ} \mathrm{C}$. According to the mass spectrometric analysis (Figure 2), at this temperature, the desorbed gases contained $\mathrm{CO}_{2}$ $(\mathrm{m} / \mathrm{z}=44), \mathrm{H}_{2} \mathrm{O}(\mathrm{m} / \mathrm{z}=18)$, and $\mathrm{H}_{2}(\mathrm{~m} / \mathrm{z}=2)$. (a)

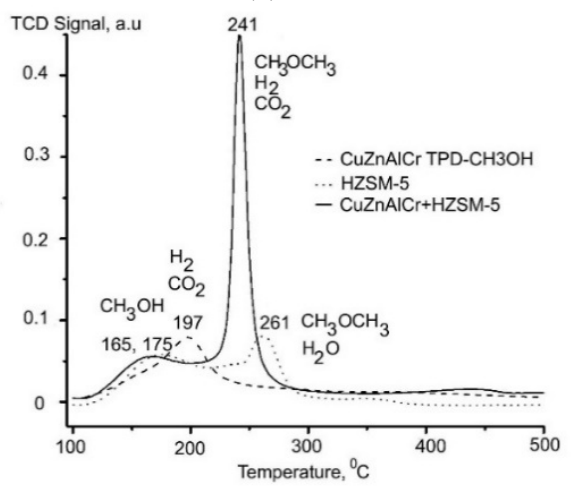

(b)

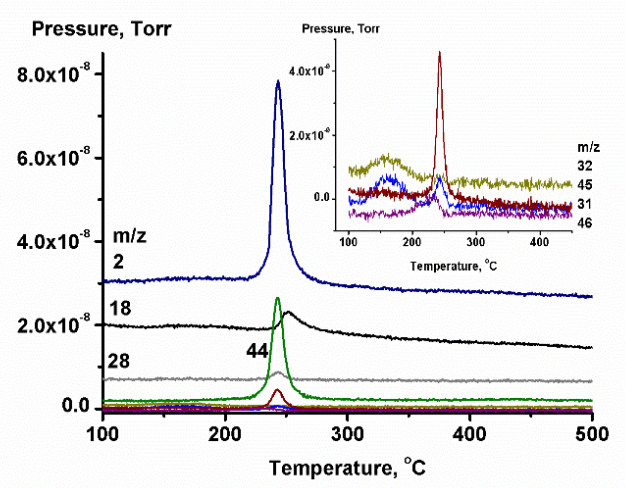

(c)

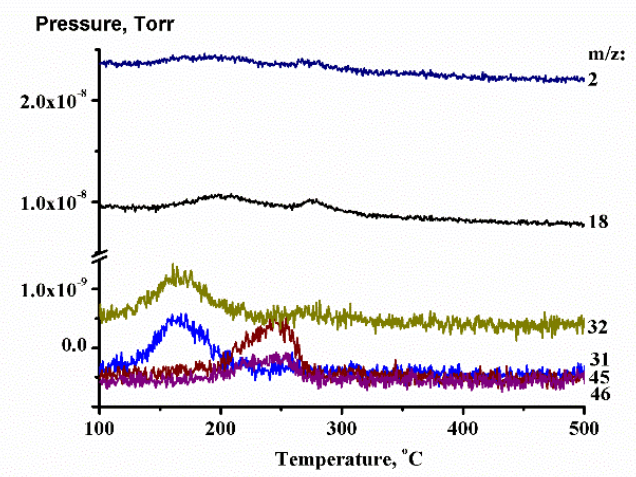

(d)

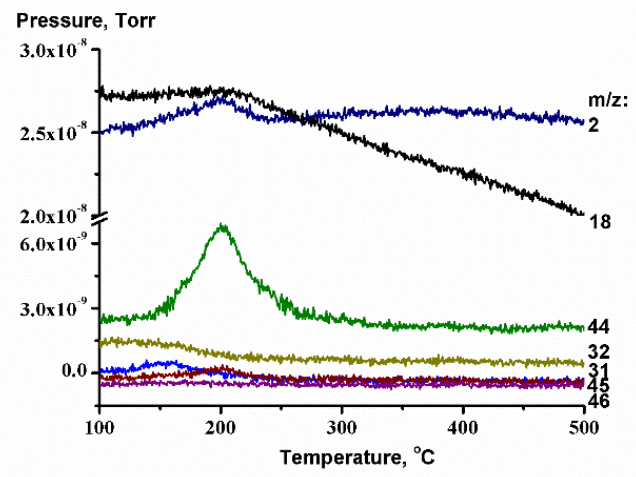

Fig. 2. (a) Methanol TPSR profiles and mass spectrometric analysis of desorption products: (b) from the surface of CZAC/HZSM-5; (c) from the surface of HZSM-5; (d) from the surface of CZAC. 
The appearance of $\mathrm{CO}_{2}$ and $\mathrm{H}_{2}$ may be due to chemical adsorption and decomposition of methanol on the surface of the copper-containing catalyst under TPSR. According to [22], aldehyde and formate complexes, formed during the chemical adsorption of methanol on copper-containing systems, can be sources of $\mathrm{CO}$ and $\mathrm{CO}_{2}$. Also, steam reforming of methanol by adsorbed water, remaining on the surface of the catalyst after its activation, was not ruled out.

The spectrum of temperature-programmed desorption of methanol from the surface of the methanol dehydration catalyst (Fig.2a, 2c) showed two most pronounced peaks at $175^{\circ} \mathrm{C}$ and $261^{\circ} \mathrm{C}$. According to the mass spectrum data, physically adsorbed methanol $\left(175^{\circ} \mathrm{C}\right)$ and adsorbed water were released first. The maximum emission of DME $(\mathrm{m} / \mathrm{z}=45$ and 46$)$ and water, formed in the methanol dehydration reaction at the active sites of the zeolite, was observed at $261{ }^{\circ} \mathrm{C}$.

The desorption spectrum of methanol from the BC surface had two peaks. The physically adsorbed methanol was released at $165^{\circ} \mathrm{C}$ (Figures $2 \mathrm{a}$ and $2 \mathrm{~b}$ ). The intensive maximum at $241{ }^{\circ} \mathrm{C}$ was due to appearance of DME, hydrogen, and carbon dioxide. DME was formed as a result of the methanol dehydration on the zeolite component of the catalyst.

The formation of DME and water on the BC surface occurred at a lower temperature $\left(241^{\circ} \mathrm{C}\right)$ than on the zeolite $\left(261^{\circ} \mathrm{C}\right)$. At the same time, a maximum of desorption at $220 \ldots 270^{\circ} \mathrm{C}$ from the surface of the $\mathrm{BC}$ was accompanied by appearance of $\mathrm{CO}_{2}$ and $\mathrm{H}_{2}$. These products were formed as a result of surface reactions of methanol. In the same temperature range, methanol and ether could be reformed to form hydrogen and carbon dioxide [23-32]. According to the TPSR spectra, it was possible to suggest a synergistic effect of two components of the $\mathrm{BC}$, which facilitates catalytic behaviour at their interfaces.

The TPSR spectra of DME from the surface of CZAC, HZSM-5, and CZAC/HZSM-5 are shown in Fig.3. The presence of two broad low-intensity desorption peaks at $150 \ldots 220^{\circ} \mathrm{C}$ and $220 \ldots .500{ }^{\circ} \mathrm{C}$, corresponding to appearance of $\mathrm{CO}_{2}$ and $\mathrm{H}_{2} \mathrm{O}$ on the mass spectrum, could be noted on the TPSR spectrum from the surface of the methanol synthesis catalyst.

The TPSR spectrum of DME from the surface of HZSM- 5 had a peak at $283{ }^{\circ} \mathrm{C}$ with a broad shoulder at $112 \ldots .255^{\circ} \mathrm{C}$. The broad shoulder in this temperature range was associated with DME desorption, accompanied by the release of water and hydrogen from various adsorption sites. (a)

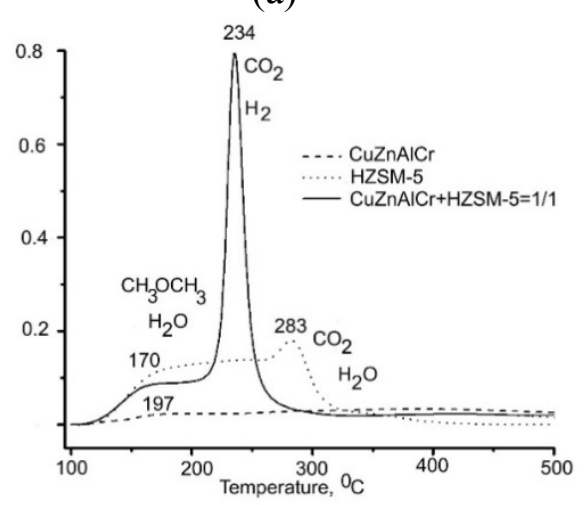

(b)

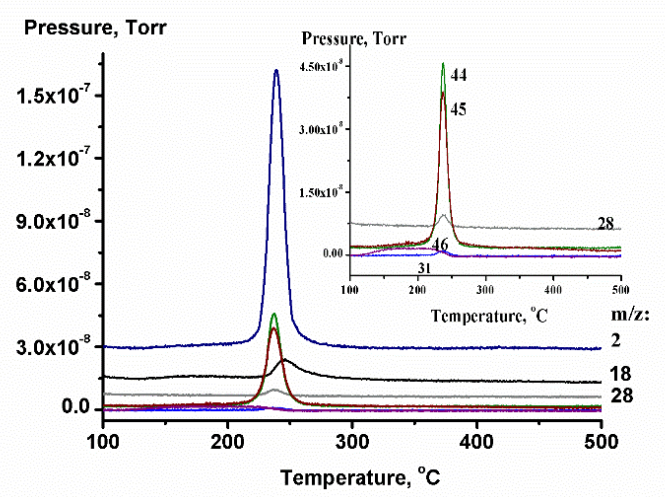

(c)

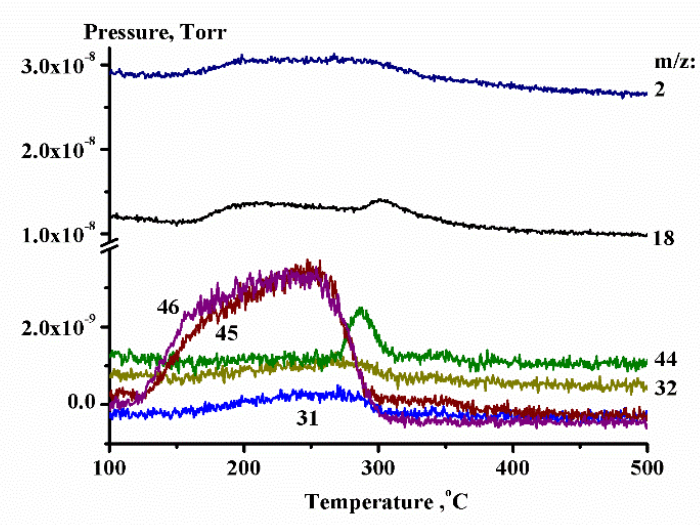

(d)

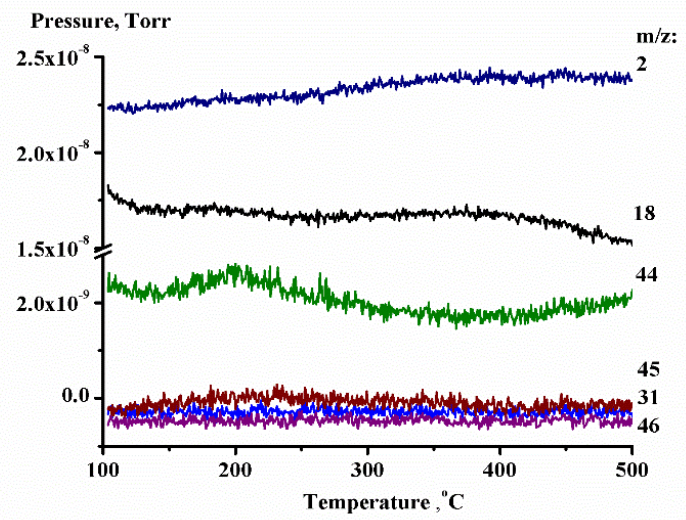

Fig. 3. (a) DME TPSR profiles and mass spectrometric analysis of desorption products: (b) from the surface of CZAC/HZSM-5; (c) from the surface of HZSM-5; (d) from the surface of CZAC. 
The peak at $283{ }^{\circ} \mathrm{C}$ corresponded to desorption of carbon dioxide and water due to surface reactions. The TPSR spectrum of DME from the surface of the BC had a broad shoulder at $120-200{ }^{\circ} \mathrm{C}$. This shape and position corresponded to the processes that occurred on the zeolite that were accompanied by desorption of DME and water. The intense peak with a maximum at $234{ }^{\circ} \mathrm{C}$ was due to desorption of DME, water, hydrogen, and carbon dioxide. Appearance of $\mathrm{H}_{2}$ and $\mathrm{CO}_{2}$ in the desorption products could be related to DME reforming on the surface of the BC. As is known, the hydrolysis of DME to methanol is possible on the acid catalyst, and methanol reforms to $\mathrm{CO}_{2}$ and $\mathrm{H}_{2}$ on the $\mathrm{CuZnAl}$-oxide catalyst. The absence of DME hydrolysis on the zeolite was explained by the fact that the water necessary for the reaction appeared in the reaction system as a result of activation of the copper-containing catalyst [23-32].

The shape and temperature range on TPSR spectra of DME (Fig.3a) were close to methanol under experimental conditions (Fig.2a). It could be assumed that dehydration of methanol and reforming of DME occurred on the same surface sites of the BC. The BC promoted both direct and reverse conversion, which indicated its high catalytic activity and explained the high content of byproducts in products of the direct synthesis of DME.

Based on the literature [23, 24] and this study, it was possible to assume the following surface reactions:

$$
\begin{aligned}
& \mathrm{CH}_{3} \mathrm{OCH}_{3}+\mathrm{OHS} \leftrightarrow \mathrm{CH}_{3} \mathrm{OS}+\mathrm{CH}_{3} \mathrm{OH} \\
& \mathrm{CH}_{3} \mathrm{OCH} \mathrm{H}_{3}+\mathrm{OS} \leftrightarrow 2 \mathrm{CH}_{3} \mathrm{OS} \\
& \mathrm{CH}_{3} \mathrm{OH}+\mathrm{OHS} \leftrightarrow \mathrm{CH}_{3} \mathrm{OS}+\mathrm{H}_{2} \mathrm{O} \\
& \mathrm{CH}_{3} \mathrm{OS}+\mathrm{OHS} \leftrightarrow \mathrm{HCOOS}+\mathrm{HS}+\mathrm{H}_{2} \\
& \mathrm{CH}_{3} \mathrm{OS}+\mathrm{OS} \leftrightarrow \mathrm{HCOOS}+2 \mathrm{HS} \\
& \mathrm{HCOOS} \leftrightarrow \mathrm{CO}_{2}+\mathrm{HS} \\
& \mathrm{HCOOS}+\mathrm{OHS} \leftrightarrow \mathrm{CO}_{2}+\mathrm{H}_{2} \mathrm{O} \\
& \mathrm{CH}_{3} \mathrm{OS} \leftrightarrow \mathrm{H}_{2} \mathrm{COS}+\mathrm{HS} \\
& \mathrm{CH}_{3} \mathrm{OS}+\mathrm{OS} \leftrightarrow \mathrm{H}_{2} \mathrm{COS}+\mathrm{OHS} \\
& \mathrm{H}_{2} \mathrm{COS}+2 \mathrm{OS} \leftrightarrow \mathrm{CO}_{2}+\mathrm{H}_{2} \mathrm{O} \\
& \mathrm{HS}+\mathrm{HS} \leftrightarrow \mathrm{H}_{2} \\
& \mathrm{HS}+\mathrm{OHS} \leftrightarrow \mathrm{H}_{2} \mathrm{O} \\
& 2 \mathrm{OHS} \leftrightarrow \mathrm{H}_{2} \mathrm{O}+\mathrm{OS} .
\end{aligned}
$$

\section{Conclusion}

Catalytic systems of the bifunctional type were obtained in the work. It was shown that BC obtained by physical mixing of $\mathrm{CuZnAl}(\mathrm{Cr} / \mathrm{Zr})-\mathrm{O}_{\mathrm{x}}$ and $\mathrm{HZSM}-5$ components were active in direct synthesis of DME from hydrogen and carbon oxide. Using physico-chemical methods, it was shown that the composition and the structure of the synthesized catalysts for the production of methanol and DME changed during catalysis. Structural rearrangements were observed as crystalline phases increased. Adding $\mathrm{Cr}$ and $\mathrm{Zr}$ caused the processes of structure formation in the catalysts in the reaction medium and were the structure-promoting additives.

When the data on the nature of the interaction of methanol and DME with the surface of the $\mathrm{BC}$ were taken into account, it could be noted that the catalyst exhibited the greatest catalytic activity at $240-260{ }^{\circ} \mathrm{C}$.
According to the TPSR, the use of a BC made it possible to reduce the dehydration temperature of the methanol prepared from syngas as compared with the dehydration of methanol on the HZSM-5 catalyst. The resulting catalysts can be promising for use in industrial processes.

This research (project No. 8.2.10.2018) was carried out with the support of the Program of increasing the competitiveness of TSU.

\section{References}

1. Dimethyl Ether, Alternative Fuels Data Center, https://www.afdc.energy.gov/fuels/emerging_d me.html

2. $\mathrm{Fu}$ Qiang, Zhang Xiaoxin, Luo Ibin, $\mathrm{Mu}$ Xuhong, Zong Baoning. RF Patent No. 2516702C2 (26 November 2009)

3. M. Lachowska, J. Skrzypek, React. Kinet. Catal. Lett. 83, 269 (2004)

4. J. Sloczynski, R. Grabowski, A. Kozłowska, P. Olszewski, M. Lachowska, J. Skrzypek, J. Stoch Appl. Catal. A. 129, 249 (2003)

5. M. C.J. Bradford, M.V. Konduru, D.X. Fuentes, Fuentes Fuel Chemistry Division Preprints 137, 47 (2002)

6. A. Venugopal; J. Palgunadi; K. D. Jung; OhShim Joo; Chae-Ho Shin, Catal Lett. 142, 123 (2008)

7. M. C.J. Bradford, M.V. Konduru, D.X. Fuentes, Fuentes Fuel Processing Technol. 11, 83 (2003)

8. J. Čejka, G. Centi, J. Perez-Pariente, W.J. Roth, Catalysis Today. 2, 179 (2012)

9. M. Xu, J.H. Lunsford, D.W. Goodman, A. Bhattacharyya, Appl. Catal. A. 289, 2 (1997)

10. F. Yaripour, F. Baghaei, I.B. Schmidt, J. Perregaard, Catal. Commun. 147, 2 (2005)

11. N.I. Kosova, P. Musich, I.A. Kurzina, A. Vosmerikov, Adv. Mater. Res., 15872 (2014)

12. P. Musich, L. Shilyaeva, L. Kurina, A. Vosmerikov, N. Kosova, Key Eng. Mater. 683, 201 (2016)

13. G. Bozga, I. T. Apan, R. E. Bozga, Recent Patents on Catalysis, 68, 2 (2013)

14. K. Saravanan, H. Ham, N. Tsubaki, J.W. Bae, Appl. Catal. B. 494217 (2017)

15. A. Ateka, J. Ereña, M. Sánchez-Contador, P. Perez-Uriarte, J. Bilbao, A.T. Aguayo, Appl.Sci,. 8, 677 (2018)

16. M. Sánchez-Contador, A. Ateka, A.T. Aguayo, J. Bilbao. J. Ind. Eng. Chem., 24563 (2018).

17. M. Aresta, A. Dibenedetto, E. Quaranta, J. Catal. 2343 (2016)

18. T.M. Yurieva, T.P. Minyukova, L.M. Plyasova, O.Yu. Prudnikova, O.V. Makarova, G.G. 
Volkova RU Patent No. 2055639 (18 June 1993)

19. I.A. Kurzina, S.I. Reshetnikov, N.I. Karakchieva, L.N. Kurina, Chem. Eng. 2 329, (2017)

20. N.I. Kosova, The process obtaining of DME from synthesis gas with use industrial catalysts for the synthesis and dehydration of methanol, $\mathrm{PhD}$ thesis (Tomsk State University, 2011).

21. F. Song, Y. Tan, H. Xie, Q. Zhang, Y. Han, Fuel Proces. Technol. 88, 126 (2014)

22. K.M. Minachev, K.P. Kotyaev, G.I. Lin, A.Y. Rozovskii, Catal. Lett. 299, 3 (1989)

23. V.A. Matyshak, L.A. Berezina, O.N. Silchenkova, V.F. Tretyakov, G.I. Lin, A.Ya. Rozovskiy, Cinetics \& Catalysis [in Russian Kinetika i Katalyz], 50, 2 (2009)

24. F. Raimondi, K. Geissler, J. Wambach, A. Wokaun, Appl. Surf. Sci. 59, 189 (2002)
25. D. Feng, Y. Wang, D. Wang, J. Wang, Chem. Eng. J., 1463 (2009)

26. K. Takeishi, H. Suzuki, Appl. Catal. A. 111 260, (2004)

27. T.A. Semelsberger, K.C. Ott, R.L. Borup, H.L. Greene, Appl. Catal. B. 291, 65 (2006)

28. Y. Tanaka, R. Kikuchi, T. Takeguchi, K. Eguchi, Appl. Catal. 211, 57 (2005)

29. T. Kawabata, H. Matsuoka, T. Shishido, D. Li, Y. Tian, T. Sano, K. Takehira, Appl. Catal. A. 82, 308 (2006)

30. K. Faungnawakij, R. Kikuchi, T. Matsui, T. Fukunaga, K. Eguchi, Appl. Catal. A. 114, 333 (2007)

31. J. Li, Q.J. Zhang, X. Long, P. Qi, Z.T. Liu, Z. W. Liu, Chem. Eng. J. 299, 187 (2012)

32. F. Dongmei, Z. Yizan, W. Dezheng, W. Jinfu, Chin. J. Chem. Eng. 223 17(1) (2009) 